\title{
Changes in renal WT-1 expression preceding hypertension development
}

Luciana Mazzei ${ }^{1,2}$, Mercedes García², Juan Pablo Calvo², Mariana Casarotto², Miguel Fornés ${ }^{3}$, María Angélica Abud², Darío Cuello-carrión ${ }^{1}$, León Ferder ${ }^{4}$ and Walter Manucha $a^{1,2^{*}}$

\begin{abstract}
Background: Hypertension is a public health problem with mostly unknown causes, and where strong hereditary genetic alterations have not been fully elucidated. However, the use of experimental models has provided valuable information. Recent evidences suggest that alterations in key nephrogenic factors, such as Wilms' tumor 1 transcription factor (WT-1), could contribute to the development of hypertension. The aim of this paper is to evaluate the expression of WT-1 and related genes in the nephrogenic process in connection with the development of hypertension as well as the corresponding anatomical and functional correlation.
\end{abstract}

Methods: Male spontaneously hypertensive and control rats were evaluated weekly from birth until week 8 of life. Their blood pressure was taken weekly using the tail-cuff blood pressure system. Weekly, 5 rats per group were sacrificed with a lethal injection of pentobarbital, and their kidneys were removed, decapsulated and weighed. The serum was collected for measuring biochemical parameters. The results were assessed using one-way analysis of variance for comparisons between groups.

Results: The relationship between renal weight/total body weights was established, without significantly different values. These data were compared with apoptosis, fibrosis, number and size of the glomeruli. The elevation of systolic blood pressure was significant since week 6 . Biochemical values differed slightly. Histology showed a slight increase in deposits of collagen fibers since week 4. Additionally, in kidney cortices, the expression of WT-1, heat shock protein 70 (Hsp70) and vitamin D receptors (VDR) decreased since week 4. Finally, we demonstrated ultrastructural damage to mitochondria since week 4.

Conclusions: Our results would suggest an unprecedented link, possibly a regulatory mechanism, between WT-1 on nephrogenic alteration processes and their relationship with hypertension. Moreover, and previous to the increase in blood pressure, we demonstrated low expressions of WT-1, VDR and Hsp70 in kidneys from neonatal SHRs. If so, this may suggest that deregulation in the expression of WT-1 and its impact on nephrogenesis induction could be crucial in understanding the development and maintenance of hypertension.

Keywords: Hypertension, Nephrogenesis, Wilms' tumor 1 factors, Heat shock protein 70, Vitamin D receptor, Mitochondria

\footnotetext{
* Correspondence: wmanucha@yahoo.com.ar

${ }^{1}$ National Scientific and Technical Research Council, Institute of Medical and

Experimental Biology of Cuyo, Mendoza, Argentina

${ }^{2}$ Pathology Department, Pharmacology Area Medical Sciences College,

National University of Cuyo, Mendoza CP5500, Argentina

Full list of author information is available at the end of the article
} 


\section{Background}

Hypertension is one of the most complex diseases to understand due to its strong genetic component. Although the genetic basis of the disease is firmly established and there have been very important developments in the field of molecular biology in recent years, few studies deal with hypertension as a result of possible changes in renal development by decoupling organogenic key factors [1]. In this regard, nephrogenic impairment is often associated with low birth weight and has been recognized as a powerful risk factor for kidney disease with low glomerular filtration rate, which would condition a more rapid progression of kidney disease and hypertension [2]. Of special interest is the fact that one important consequence of the altered nephrogenic process is hypertension. Kidney damage is a significant event in the development of hypertension and, thus, maternal food restriction alters key fetal nephrogenesis gene expression, such as Wilms' tumor transcription factor 1 (WT-1) and other factors; this appears to contribute to hypertension development [3, 4]. In addition, some genes involved in hypertension development also depend on WT-1. The fact that renin gene transcription is regulated by WT-1, and that inherited mutations in the WT-1 gene can lead to hypertension, may explain the findings of patients with high renin and hypertension [5]. Accordingly, unpublished results from our laboratory assays performed in adult spontaneously hypertensive rats (SHRs) suggested an opposite relationship between WT-1 renal expression and blood pressure values. Furthermore, recent hypertension studies show low levels of vitamin D associated with the exaltation of the renin-angiotensin-aldosterone system (RAAS) [6-8]; and, in that respect, our laboratory has demonstrated, in the primary culture of proximal tubular cells of SHRs, that heat shock protein 70 (Hsp70) protects against hypertension induced by angiotensin II by exerting a cytoprotective effect [9]. We have also demonstrated in adult SHRs that the induction of vitamin $\mathrm{D}$ receptor (VDR) modulates an increase in Hsp70 levels, with a decrease in the angiotensin II receptor, type $1\left(\mathrm{AT}_{1}\right)$ expression, providing renal protection [10]. These contributions are relevant considering previous reports, where WT-1 and Hsp70 are physically associated (localized) in embryonic rat kidney cells, in primary Wilms' tumor samples, and in cultured cells with inducible WT-1 expression [11]. It has also been described that Hsp70 is an important cofactor for the function of WT-1, and suggested a potential role for this chaperone during nephrogenesis. Furthermore, it has been reported that human VDR is regulated by WT-1 [12]. These findings strengthen our recent demonstrations in the adult SHR model. Here we established, in mitochondria, a significant and consistent anatomical-functional correlate with the expression of the markers/modulators mentioned above $\left(\mathrm{AT}_{1}, \mathrm{VDR}\right.$ and Hsp70) [10]. Moreover, cumulative evidence suggests that reactive oxidative stress (ROS) and inflammation, with particular attention to mitochondria, plays an important role in hypertension development [13, 14]. In this regard, our laboratory reviewed and proposed a complex new regulation in the inflammatory pathway that involves the possible modulation of Hsp70 and WT-1 on mitochondrial signaling and where the net effect would favor cell survival by WT-1 stabilizing $\mathrm{Bcl}_{2}$, and would limit the potential for the release of cytochrome $C$ from mitochondria [15].

Finally, SHRs were originally inbred from Wistar rats and their Wistar-Kyoto (WKY) inbred non-hypertensive controls. These rats develop hypertension at about 6 weeks of age without physiological, pharmacological or surgical intervention; however, environmental factors affect the development of hypertension, and the importance of this model has been attributed to the similarity of its pathophysiology with essential hypertension in humans [16].

Based on the arguments stated above, we finally proposed to evaluate the following key hypothesis: Changes in the expression pattern of the WT-1 transcription factor and molecular mediators related to nephrogenesis could contribute to anatomical and functional kidney disorders, as well as to a hemodynamics disorders typical of the SHR model. Such modifications could respond to a Hsp70-dependent conditioning, as well as a probable modulation of the vitamin $\mathrm{D}$ receptor. In addition, we discuss the possibility that mitochondrial injury and dysfunction linked to master nephrogenic factors, such as WT-1, could play a central role in the pathogenesis of the essential hypertension model.

\section{Methods}

Both the SHR group and the control group, formed by Wistar Kyoto rats (WKY), were cared in accordance with the Guiding Principles in the Care and Use of Animals of the United States National Institute of Health. All experimental procedures were previously approved by the Institutional Animal Care and Use Committee of the Medical Sciences College, National University of Cuyo (Protocol approval No 46/2015).

\section{Animals}

Newborn male SHRs $(n=45)$ and WKYs $(n=45)$, were evaluated during their first 8 weeks of life (from birth, i.e. week 0 , to week 8 ). Their blood pressure was taken weekly using the CODA tail-cuff blood pressure system (Kent Scientific Corporation). Weekly, 5 rats per group (SHR and WKY), were sacrificed with a lethal injection of pentobarbital, and their kidneys were removed, decapsulated and weighed. The serum was collected 
for measuring biochemical parameters. The serum urea and creatinine concentrations were determined using colorimetric assays (Sigma kits).

\section{Histological studies}

Sections of the renal cortex were processed for histological studies according to previously described [17].

\section{Morphometric evaluation of interstitial fibrosis}

For all morphologic evaluations, the observer was blinded to the origin of the histological sections. A standard point counting method was used to quantitate the fibrosis of the renal interstitium [18-20]. Results were expressed as percentage of measured area.

\section{Glomerular morphometric analysis}

Masson's trichrome stained sagittal sections of the rat kidney cortices were scanned under light microscopy with a zig-zag movement so as to assure equal sampling of the cortex and to avoid evaluating the same glomerulus twice. The morphometric parameters were evaluated as previously [19], with minor modifications. The relative number of glomeruli per square millimeter of renal cortex was calculated. A reticulate eyepiece was used for counting glomeruli. To avoid double counting, glomeruli crossed by the upper and left margins of the reticle were counted in 10 fields of tissue section. The number of glomeruli per microscopic field was counted in every section observed (100 fields). To assess the relative glomerular diameter, a micrometric eyepiece was used. Ten tissue sections per microscopic field were taken at random. The diameters were expressed in micrometers $(\mu \mathrm{m})$.

\section{Identification of cellular apoptosis: the TUNEL technique} Cellular apoptosis by terminal deoxynucleotidyl transferase-mediated dUTP nick end labeling technique was performed according to previously reported [20].

\section{Electron microscopy}

The tissue samples were processed for electron microscopy according to previously described methodology with minor modifications [20].

\section{Immunohistochemical studies}

Kidney paraffin sections were processed according to previously described technique with minor modifications [21]. The antibodies applied were rabbit polyclonal antibody against WT-1 (C-19), mouse monoclonal antibody against VDR (D-6), rabbit polyclonal antibody against Hsp70 (H-300) and rabbit polyclonal antibody against $\mathrm{AT}_{1}$ (306) (Santa Cruz Biotechnology, Inc.), diluted at 1:500. A commercial immunoperoxidase kit was used (Dako). The positive reaction was evaluated considering the specific location of the immunostaining and the intensity of the immunoreaction. The negative controls included tissues unexposed to primary antibodies as well as tissues exposed to control immunoglobulin G. The positive controls were human breast cancer biopsy samples. The immunostaining was evaluated and resolved by consensus according to a scoring system reported previously $[22,23]$.

\section{Immunofluorescence confocal microscopy}

The kidneys were processed according to previously described technique [21]. Primary antibodies were: polyclonal anti-WT-1 (1:100) (Santa Cruz Biotechnology), monoclonal anti-Hsp70 (1:100) (Sigma Aldrich), monoclonal anti-VDR (1:100) (Santa Cruz Biotechnology), and polyclonal anti-AT 1 (1:100) (Santa Cruz Biotechnology). Secondary antibodies were: goat anti-rabbit IgG antibody, Cy2 conjugated (1:750) and donkey anti-mouse IgG antibody, Cy3 conjugated (1:750). After being washed, the tissues were stained with Hoechst 33342 (10 $\mathrm{nM})$ for $5 \mathrm{~min}$. The coverslips were mounted in Fluoroshield solution (Sigma Aldrich) for confocal microscopy. Confocal images were taken using FV10-ASW 1.7 (Olympus IX81 microscope).

\section{Mitochondria isolation from tissue}

Mitochondria isolation and purity of mitochondrial fractions were established as previously described [24, 25] with minor modifications.

\section{NADPH activity assay}

$\mathrm{NADPH}$ oxidase activity was measured in enriched mitochondrial fractions of the renal cortex using the Luminol (5-amino-2, 3-dihydro-1, 4-phthalazine; SigmaAldrich) technique. The values were expressed as relative fluorescence units (RFU) per microgram of protein and per minute of incubation.

\section{Statistical analysis}

The results were assessed using one-way analysis of variance (ANOVA) for comparisons between groups. Differences between groups were determined using the Bonferroni posttest. A $p<0.05$ was considered to be significant. Results are given as mean \pm standard error of the mean (SEM). Statistical tests were performed using GraphPad InStat version 3.00 for Windows 95 (GraphPad Software, Inc., La Jolla, California, United States of the America).

\section{Results}

\section{Weight, hemodynamics and serum chemistry}

The body weights in each strain increased rapidly from newborn to 8 weeks of life. However, the differences in body weights between the two strains were enlarged 
after week 6 , and by week 8 the SHRs and WKYs weighed $160 \pm 10 \mathrm{~g}$ and $190 \pm 12 \mathrm{~g}(p<0.05)$, respectively ( $n=5$ per week/per group). We also evaluated the renal weight/total body weight ratio, and found no significant differences between the strains (SHR vs. WKY; $p=\mathrm{NS}$ ) in the weeks studied ( $n=5$ per week/per group). On the other hand, due to the low weight of the animals, we could only measure the systolic blood pressure (SBP) accurately since week 4 of life until the end of the study (week 8). The SBP in both strains, SHR and WKY, was $195 \pm 10$ vs. $145 \pm 8 \mathrm{mmHg} ; p<0.05$ at week 6 . Thereafter, the blood pressure of the SHRs elevated to $250 \mathrm{mmHg}$ at week 8 . In contrast, the SBP of the WKYs was $145 \pm 8$ and $150 \pm 10 \mathrm{mmHg}$ at weeks 6 and $8(p=\mathrm{NS})(n=5$ per week/per group) (Table 1$)$.

The study of biochemical parameters $(n=5$ per week/ per group) showed an increasing tendency for both serum urea and creatinine of hypertensive rats (SHR) and their normotensive controls (WKY). However, since week 4, creatinine values in SHRs were slightly lower than in WKYs $(0.65 \pm 0.03$ vs. $0.75 \pm 0.04 \mathrm{mg} / \mathrm{dl} ; p=\mathrm{NS})$. In contrast, the values of plasma urea in SHRs were discreetly higher than in WKYs $(15 \pm 2$ vs. $13 \pm 1.6 \mathrm{mg} / \mathrm{dl}$; $p=\mathrm{NS})$. Relevant to our study was that, at week 8 , creatinine values in SHRs were lower than in WKYs $(0.70 \pm$ 0.06 vs. $0.95 \pm 0.07 \mathrm{mg} / \mathrm{dl} ; p<0.05$ ), while the values of plasma urea in SHRs were higher than in WKYs $(20 \pm 2$ vs. $15 \pm 2 \mathrm{mg} / \mathrm{dl} ; p<0.05$ ) (Table 2 ).

\section{Interstitial fibrosis, apoptosis, and ultrastructural} mitochondrial damage during hypertension development Figure 1a shows, from week 4 of life, the degree of tubulointerstitial fibrosis in the renal cortices of SHR kidneys.
Compared to those, WKY kidneys showed a lower collagen accumulation in the expanded interstitium along with cellular interstitial infiltrates in the cortex. In addition, SHR kidneys at week 8 had more significant interstitial collagen deposition compared to what was seen in WKY kidneys. The interstitial fibrotic area in SHRs revealed a twofold expansion of the interstitial space compared to WKYs $(50 \pm 8$ vs. $25 \pm 10 \% ; p<0.05$, $n=5)$ (Fig. 1a).

Figure 2a shows, from week 4 of life, an increased number of TUNEL-positive apoptotic cells in tubular epithelial cells from SHRs compared to those from WKYs. Interestingly, the number of TUNEL-positive apoptotic cells in 8-week-old SHRs was significantly higher than the number found in WKYs $(30 \pm 4$ vs. $18 \pm$ 4; $\mathrm{p}<0.05, n=5$ ) (Fig. 2a).

Figure 3 shows the results of the electron microscopy study. In 4-week-old SHRs, the proximal convoluted tubules display normal tubular cells with baseline projections within normal parameters. They had abundant mitochondria, mostly with normal ultrastructure, except that some begin to show changes, such as wider spaces than expected between the mitochondrial cristae (luminescent spaces larger than usual, arrow). Conversely, in 4-week-old WKYs, the space between cristae was normal. On the other hand, the architecture of the renal tissue obtained from 8-week-old SHRs was composed of disorganized cortical tubules, and the cellular structure was also altered. These cells contained vacuoles of different sizes, mitochondria with cristae (arrow in SHR) separated by widened spaces between them -some of them containing vacuoles and dense bodies surrounded by membranes. In 8 -week-old WKYs, the cytoplasm and

Table 1 Body weight, kidney/body weight ratio, and blood pressure in SHRs and WKYs

\begin{tabular}{|c|c|c|c|c|c|c|c|c|c|}
\hline Strain & $\begin{array}{l}\text { 0-week-old } \\
\text { rat }\end{array}$ & $\begin{array}{l}\text { 1-week-old } \\
\text { rat }\end{array}$ & $\begin{array}{l}\text { 2-week-old } \\
\text { rat }\end{array}$ & $\begin{array}{l}\text { 3-week-old } \\
\text { rat }\end{array}$ & $\begin{array}{l}\text { 4-week-old } \\
\text { rat }\end{array}$ & $\begin{array}{l}\text { 5-week-old } \\
\text { rat }\end{array}$ & $\begin{array}{l}\text { 6-week-old } \\
\text { rat }\end{array}$ & $\begin{array}{l}\text { 7-week-old } \\
\text { rat }\end{array}$ & $\begin{array}{l}\text { 8-week-old } \\
\text { rat }\end{array}$ \\
\hline \multicolumn{10}{|l|}{ SHR } \\
\hline Body weight (g) & $6 \pm 1$ & $13 \pm 3$ & $24 \pm 4$ & $45 \pm 6$ & $82 \pm 7$ & $100 \pm 10$ & $130 \pm 9^{*}$ & $150 \pm 9^{*}$ & $160 \pm 10^{*}$ \\
\hline \multicolumn{10}{|l|}{ WKY } \\
\hline Body weight (g) & $7 \pm 1$ & $17 \pm 4$ & $29 \pm 5$ & $54 \pm 7$ & $92 \pm 8$ & $115 \pm 9$ & $150 \pm 8$ & $175 \pm 10$ & $190 \pm 12$ \\
\hline \multicolumn{10}{|l|}{ SHR } \\
\hline $\begin{array}{l}\text { Renal/Body weight } \\
(\mathrm{mg} / \mathrm{g})\end{array}$ & $5.60 \pm 0.3$ & $6.05 \pm 0.90$ & $5.9 \pm 1.00$ & $5.86 \pm 0.90$ & $6.02 \pm 1.10$ & $7 \pm 1.30$ & $7.7 \pm 1.00$ & $7.5 \pm 1.20$ & $8 \pm 1.20$ \\
\hline \multicolumn{10}{|l|}{ WKY } \\
\hline $\begin{array}{l}\text { Renal/Body weight } \\
(\mathrm{mg} / \mathrm{g})\end{array}$ & $6.1 \pm 0.30$ & $7.43 \pm 1.10$ & $6.66 \pm 1.10$ & $6.9 \pm 1.20$ & $6.82 \pm 1.20$ & $6.3 \pm 1.20$ & $7.3 \pm 1.10$ & $6.7 \pm 1.10$ & $7.3 \pm 1.10$ \\
\hline \multicolumn{10}{|l|}{ SHR } \\
\hline $\mathrm{SBP}(\mathrm{mmHg})$ & -二-二 & -二-二 & -二- - & - - - - & $142 \pm 11$ & $150 \pm 10$ & $195 \pm 10^{* *}$ & $230 \pm 15^{* *}$ & $250 \pm 20^{* *}$ \\
\hline \multicolumn{10}{|l|}{ WKY } \\
\hline $\mathrm{SBP}(\mathrm{mmHg})$ & -二-二 & -二-二- & -二-二- & -二-二- & $135 \pm 8$ & $140 \pm 7$ & $145 \pm 8$ & $148 \pm 7$ & $150 \pm 10$ \\
\hline
\end{tabular}

Significantly different from the values at 6,7 and 8 weeks of age in each strain ${ }^{*} p<0.05$ and $\left.{ }^{* *} p<0.01\right)$. Results are mean \pm SEM; $n=5$ 
Table 2 Biochemical parameters in SHRs and WKYs

\begin{tabular}{|c|c|c|c|c|c|c|c|c|c|}
\hline Strain & $\begin{array}{l}\text { 0-week-old } \\
\text { rat }\end{array}$ & $\begin{array}{l}\text { 1-week-old } \\
\text { rat }\end{array}$ & $\begin{array}{l}\text { 2-week-old } \\
\text { rat }\end{array}$ & $\begin{array}{l}\text { 3-week-old } \\
\text { rat }\end{array}$ & $\begin{array}{l}\text { 4-week-old } \\
\text { rat }\end{array}$ & $\begin{array}{l}\text { 5-week-old } \\
\text { rat }\end{array}$ & $\begin{array}{l}\text { 6-week-old } \\
\text { rat }\end{array}$ & $\begin{array}{l}\text { 7-week-old } \\
\text { rat }\end{array}$ & $\begin{array}{l}\text { 8-week-old } \\
\text { rat }\end{array}$ \\
\hline \multicolumn{10}{|l|}{ SHR } \\
\hline \multicolumn{10}{|c|}{ Creatinine } \\
\hline (mg/dl) & $0.49 \pm 0.08$ & $0.51 \pm 0.07$ & $0.55 \pm 0.06$ & $0.60 \pm 0.05$ & $0.65 \pm 0.03$ & $0.67 \pm 0.09$ & $0.68 \pm 1.00$ & $0.70 \pm 0.09$ & $0.70 \pm 0.06^{*}$ \\
\hline \multicolumn{10}{|l|}{ WKY } \\
\hline \multicolumn{10}{|c|}{ Creatinine } \\
\hline (mg/dl) & $0.55 \pm 0.07$ & $0.60 \pm 0.08$ & $0.65 \pm 0.06$ & $0.70 \pm 0.07$ & $0.75 \pm 0.04$ & $0.79 \pm 0.09$ & $0.85 \pm 0.09$ & $0.90 \pm 1.10$ & $0.95 \pm 0.07$ \\
\hline \multicolumn{10}{|l|}{ SHR } \\
\hline \multicolumn{10}{|l|}{ Urea } \\
\hline (mg/dl) & $12 \pm 1.00$ & $13 \pm 1.00$ & $14 \pm 2.00$ & $15 \pm 2.00$ & $15 \pm 2.00$ & $16 \pm 2.00$ & $18 \pm 3.00$ & $20 \pm 3.00$ & $20 \pm 2.00^{*}$ \\
\hline \multicolumn{10}{|l|}{ WKY } \\
\hline \multicolumn{10}{|l|}{ Urea } \\
\hline$(\mathrm{mg} / \mathrm{dl})$ & $11 \pm 1.00$ & $12 \pm 2.00$ & $12 \pm 2.00$ & $13 \pm 2.00$ & $13 \pm 1.60$ & $14 \pm 2.00$ & $14 \pm 2.00$ & $15 \pm 4.00$ & $15 \pm 2.00$ \\
\hline
\end{tabular}

Significantly different from the values at 8 weeks of age in each strain $\left({ }^{*} p<0.05\right)$. Results are mean \pm SEM; $n=5$

mitochondria showed a normal appearance for this type of cell and, in addition, the cortical area of the renal tissue was well-preserved.

\section{Effects of hypertension development on glomerular morphometry}

Figure 4 shows the evaluation of glomerular morphometry. A slight decrease in the number of glomeruli was found in 4-week-old SHRs in relation to WKYs $(10 \pm 1.5$ vs. $13.5 \pm 1.5 ; p=\mathrm{NS})$. Similarly, a slight decrease in the relative glomerular diameter was found in 4-weekold SHRs in relation to WKYs $(90 \pm 6$ vs. $101 \pm 4 \mu \mathrm{m}$; $p=\mathrm{NS}$ ). However, at week 8 , a significant decrease in the number of glomeruli was found in SHRs with respect to WKYs $(8 \pm 1.3$ vs. $14 \pm 2 ; p<0.05$. Likewise, a significant decrease in the relative glomerular diameter was found in SHRs with respect to WKYs $(95 \pm 6$ vs. $130 \pm 10 \mu \mathrm{m} ; p<0.05)$.

\section{Expression of WT-1, VDR, Hsp70 and AT ${ }_{1}$, and NADPH activity during hypertension development}

Immunocytochemical and immunofluorescence analyses were performed to establish protein location and immunoreaction intensity. Figures 5 and 6 show the expressions of WT-1, VDR, Hsp70 and $\mathrm{AT}_{1}$ in the cortices of SHRs and WKYs. In the renal cortices of 4-week-old SHRs, low WT-1, VDR and Hsp70 immunostaining/immunofluorescence (Figs. 5a and 6a) was observed in the epithelial cell cytoplasm. Contrary to this, $\mathrm{AT}_{1}$ staining was shown in the same epithelial cells from SHRs (Figs. 5a and 6a). These values were very significant at week 8 of the study, when a very low WT-1, VDR and Hsp70 immunostaining/immunofluorescence (Figs. 5a and 6a) was observed in the epithelial cell cytoplasm. Conversely, a very high $\mathrm{AT}_{1}$ staining was shown in the same epithelial cells from SHRs (Figs. 5a and 6a). On the other hand, in all renal cortices (4, 6 and 8-week-old) of WKYs, high WT-1, VDR and Hsp70 immunostaining/ immunofluorescence (Figs. 5b and 6b) was observed in the epithelial cell cytoplasm. Contrary to this, $\mathrm{AT}_{1}$ low staining was shown in the same epithelial cells from WKYs (Figs. 5b and 6b). These values were not significant. Conversely, a very low $\mathrm{AT}_{1}$ staining was shown in the same epithelial cells from SHRs (Figs. 5b and 6b). Furthermore, preliminary results in SHRs by western blotting and RT-PCR $(n=3)$ support these results (Additional files 1: Data S1 and 2: Data S2). Parallel to this study, Fig. 7 shows, in mitochondrial fractions from cortices at week 4 , that NADPH oxidase activity was significantly greater in SHRs than in WKYs $(13,000 \pm 500$ vs. $11,500 \pm 500 \mathrm{RFU} / \mu \mathrm{g}$ prot $/ \mathrm{min} ; p<0.05, n=5)$. Interestingly, the NADPH oxidase activity in 8-week-old SHRs was significantly higher than the activity found in the WKY group $(17,000 \pm 600$ vs. $13,500 \pm 700 \mathrm{RFU} / \mu \mathrm{g}$ prot $/ \mathrm{min} ; p<0.01, n=5)$. In consequence, the NADPH oxidase activity gradually grew throughout the study.

\section{Discussion}

This paper is the first report showing that, in the natural history of hypertension, ultrastructural mitochondrial damage occurs first, before hemodynamic clinical manifestations appear. Therefore, altered mitochondrial energy metabolism linked to master nephrogenic factors, such as WT-1, could play a central role in the essential hypertension model, and should be further investigated. The present study shows WT-1 expression in the late nephrogenic process associated with hypertension development as well as the corresponding anatomical and functional correlation. Also for the first time, previous to the increase in blood pressure, we demonstrated low 


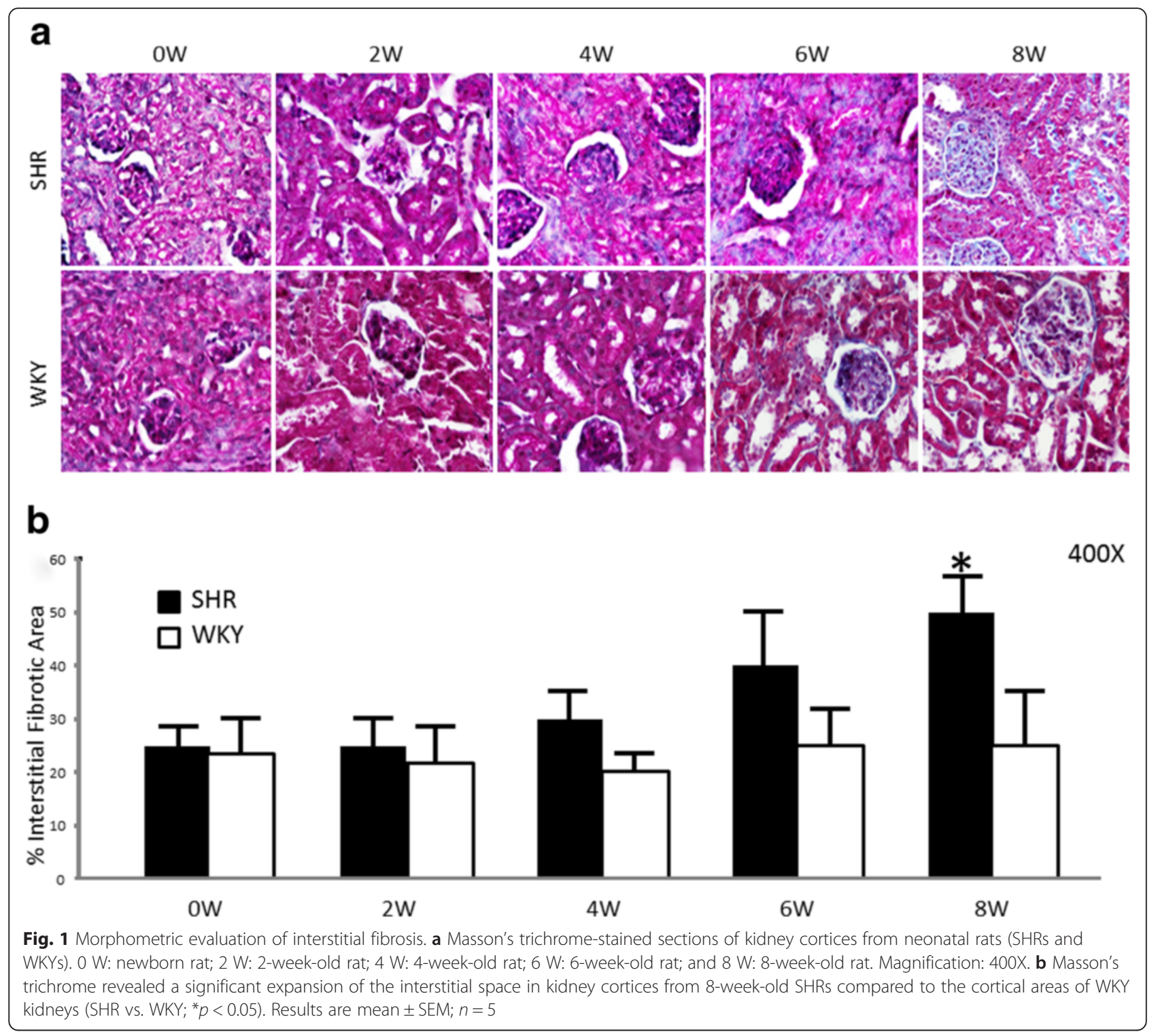

expressions of WT-1, VDR and Hsp70 in kidneys from neonatal SHRs.

As widely known, hypertension is considered one of the most important public health problems in developed countries, affecting about one billion people worldwide (9.4 million deaths/year; World Health Organization 2013). Hypertension occurs as an asymptomatic disease, although, paradoxically, many changes that precede the elevation of blood pressure produce specific organic lesions, some clinically defined. In addition, the multitude of contributing factors (environment, sodium intake, renin, insulin resistance, sleep apnea and age, among others) makes hypertension complex to study mainly due to the genetic component associated with its appearance. Of particular interest to this study is the relationship between hypertension and kidney disease, which yet remains unclear and is a matter of considerable research interest, with evidence suggesting that hypertension is both a cause and a consequence of kidney disease.

The kidney is an extremely complex structure, consisting of functional units having about 10,000 cells divided into at least 14 different cell types. This implies that the renal morphogenesis must be perfectly orchestrated, and that the conversion of mesenchymal mesodermal cells into polarized epithelial cells [26] is a critical step of this process. There is evidence that WT-1 may be directly involved in the regulation of cell proliferation and differentiation. In situ hybridization studies have shown WT-1 to be selectively expressed in the metanephric blastema and glomerular epithelium during embryonic and fetal development [27]. The expression patterns of WT-1 indicate an important role of this gene not only during 


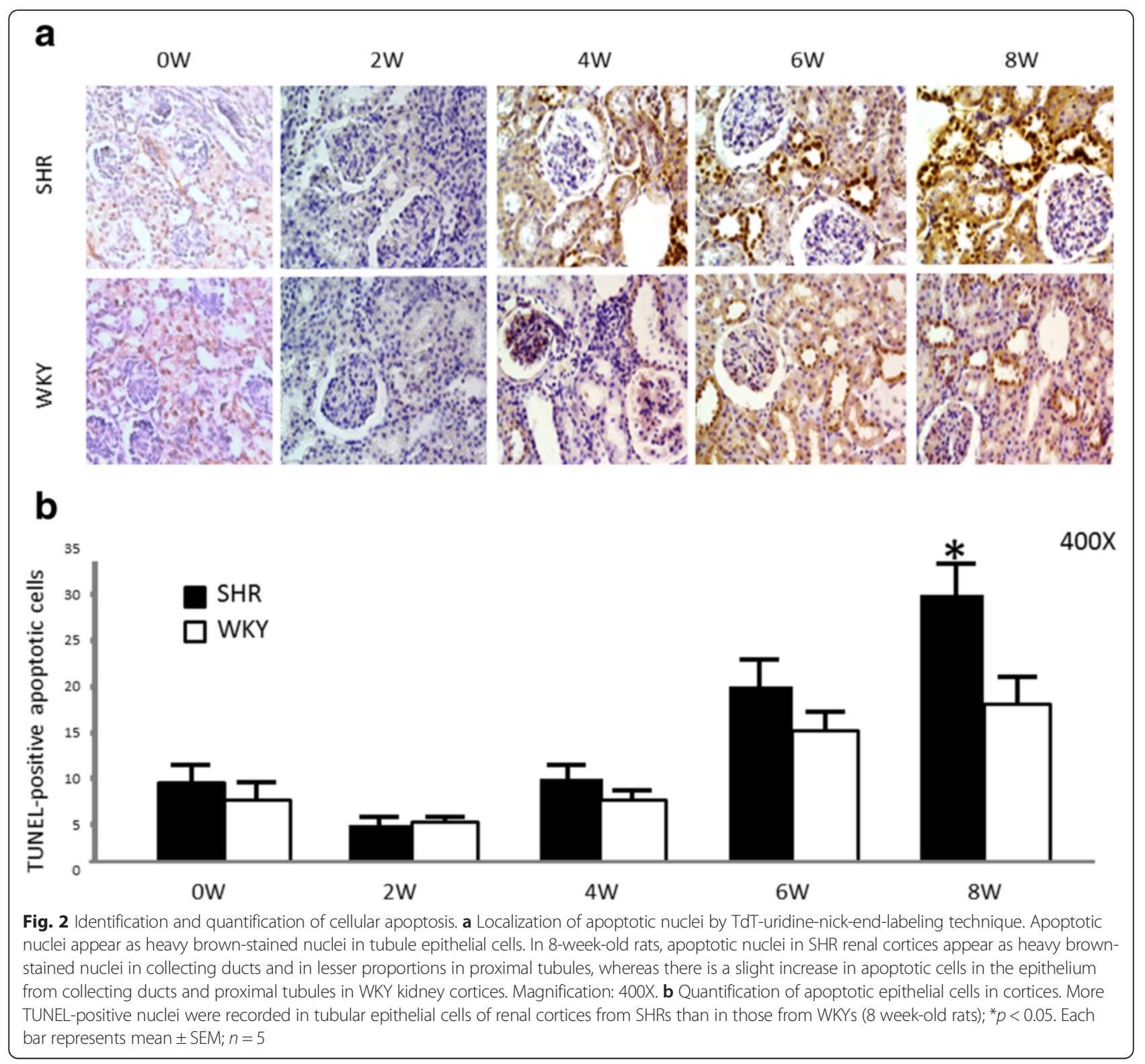

urogenital development but also during fetal and postnatal life. Furthermore, using laser microscopy techniques, WT-1 was sub-located in the nucleus cell, regardless of cell type and stage of development. Moreover, it has been concluded that the initial growth of the ureteric bud is dependent on a signal from the metanephric blastema and WT-1 would be necessary for this [28-30]. Therefore, WT-1 is essential for normal kidney development [31].

In contrast, nephrogenic deficiency has been recognized as a powerful risk factor for kidney disease, conditioning a more rapid progression of the disease and the possible development of hypertension [2]. Our group has confirmed this in the present study when quantifying/qualifying the glomeruli of SHRs compared to those of WKYs, from birth to hypertension development. Specifically, a slight decrease in the number and diameter of glomeruli was found in 4-week-old rats, while a significant decrease was found in 8-week-old rats. Similarly, we established significant changes in renal function (urea and creatinine) only in 8-week-old rats. In parallel, we could establish a close relationship of these parameters and WT-1 expression, which was clearly lowered especially in 8-week-old rats. This is consistent with previous reports from our laboratory where a low expression of WT-1 in neonatal rats with kidney disease was associated with glomerular changes and reduced nephrogenic markers such as Snail, BMP-7 and E-cadherin [32]. However, the most striking finding of the present study was to establish that, first, there were changes in WT-1 

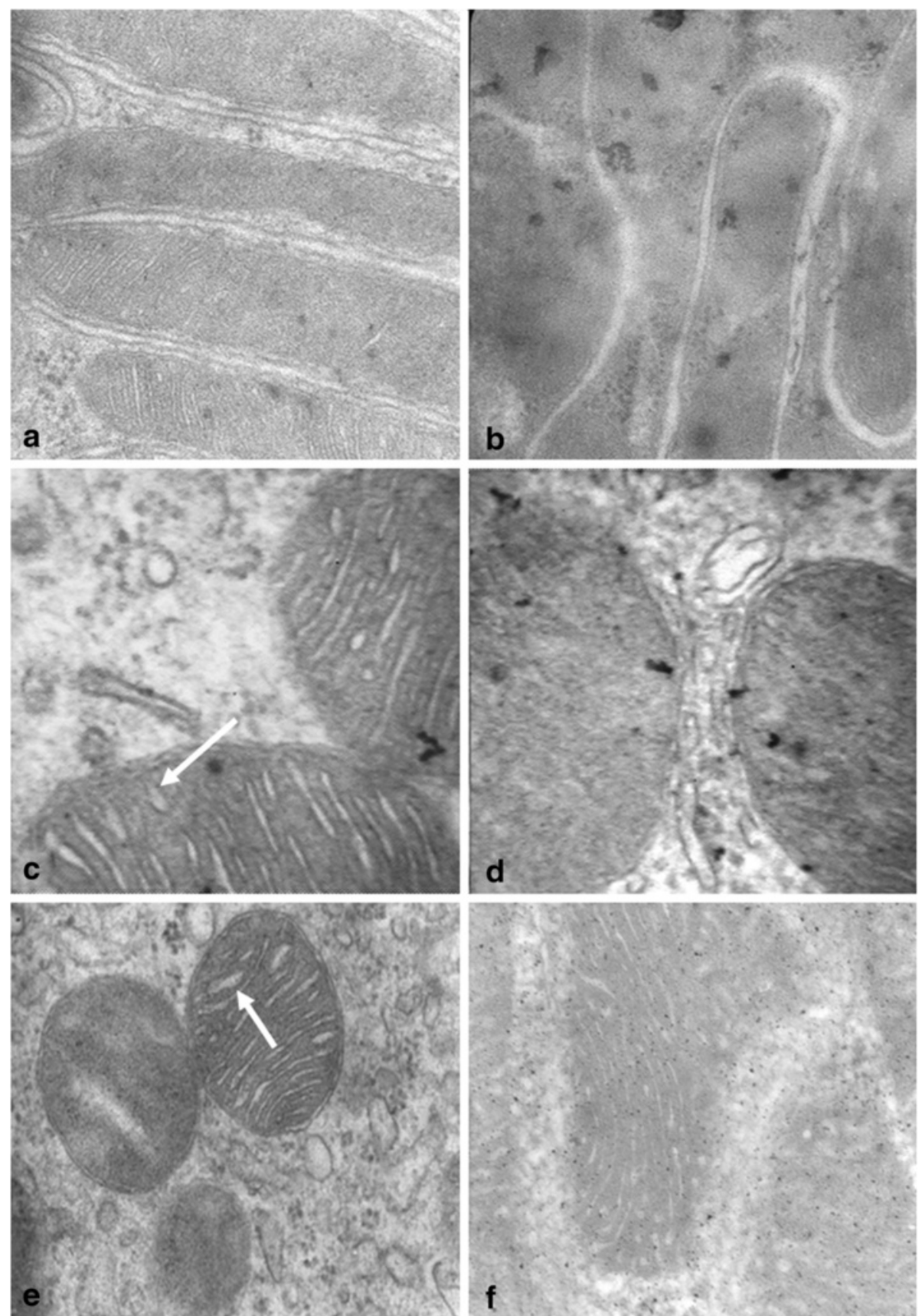

Fig. 3 Electron microscopy study in neonatal SHRs and WKYs. Effects of hypertension development in mitochondria of renal cortical cortices of newborn SHR (a) and WKY (b), 4-week-old SHR (c) and WKY (d), and 8-week-old SHR (e) and WKY (f). Note that the mitochondria present dilated mitochondrial crestae (arrows; $\mathbf{c}$ and $\mathbf{e}$ ) in the tubules of SHRs. Convoluted distal tubules of WKYs (b, $\mathbf{d}$ and $\mathbf{f}$ ) showing normal ultrastructure were included for comparison. Magnification: 60,000 (a), 58,000 (b), 70,000 (c, d and f), and 65,000 (e)

expression linked to glomerular alterations (in 4-weekold rats), and then, these were followed by hemodynamic changes with elevation of blood pressure (in 6-week-old rats). To support this, genes typically involved in the process of hypertension development are also WT-1 dependent [5,33]. Interestingly, inherited mutations in the WT-1 gene can lead to life-threatening hypertension
[5]. Thus, the renin gene transcription is regulated by the WT-1 (-KTS) protein and this could explain the findings in patients with WT-1 mutations that occur with increased plasma renin and hypertension. Therefore, and of particular interest to our current discussion, one important consequence of the altered nephrogenic process is hypertension development, which further 


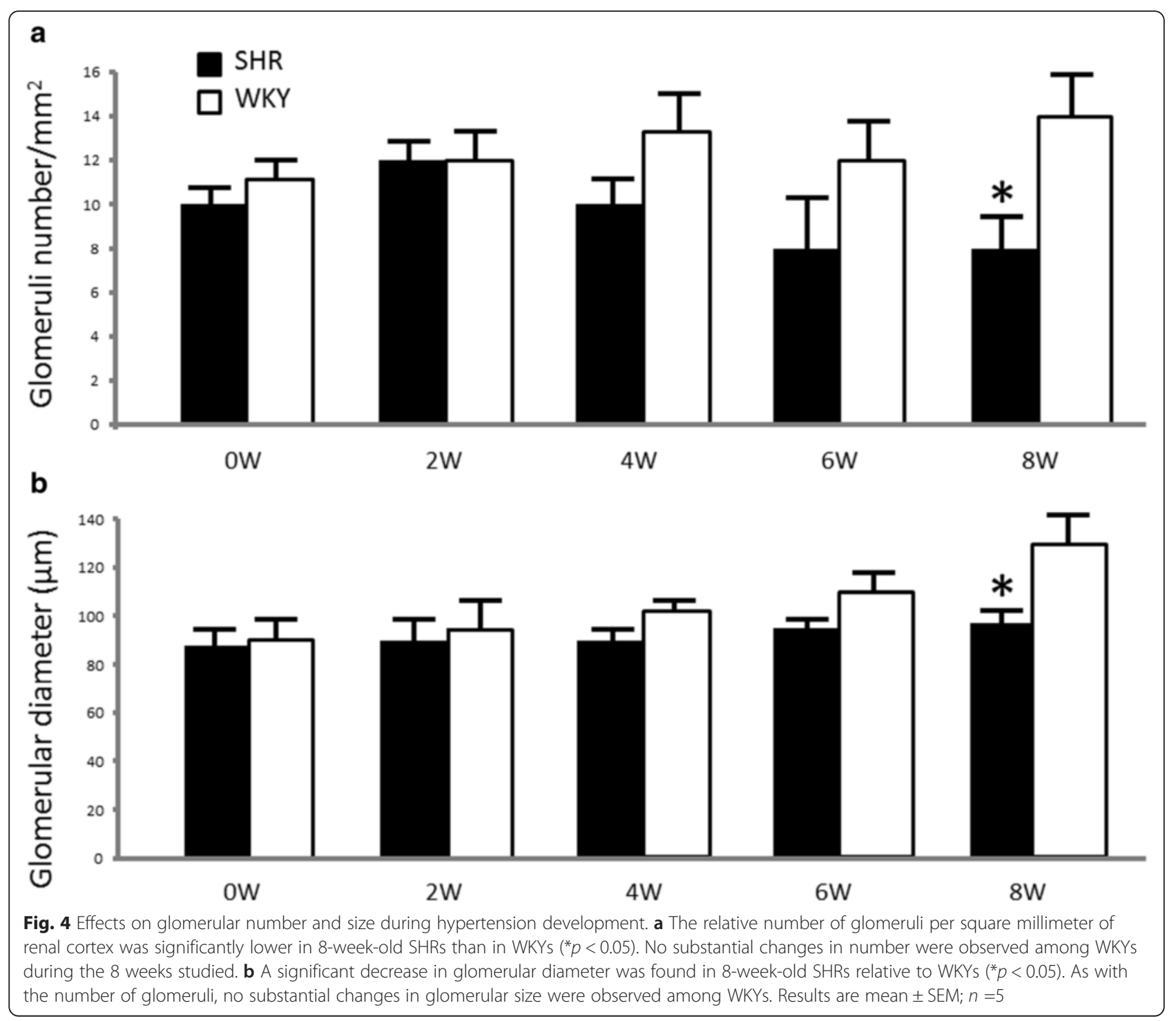

amplifies the risk of onset and progression of kidney disease [33]; this makes it controversial to analyze whether hypertension is a cause or a consequence of kidney disease.

To emphasize our findings, WT-1 plays a key role in the onset of kidney formation, the progression of kidney formation and the maintenance of normal kidney function. The WT-1 protein participates in diverse cellular processes such as proliferation, differentiation and apoptosis and, in accordance with these functions, the number of target genes and/or proteins it affects is still increasing [34]. Particularly, the cells of the glomerulus, the proximal tubules and the distal tubules all derive from the metanephric mesenchyme where WT-1 already plays an active role [35]. According to this, in addition to glomerular alteration, we also established a significant change in the morphometric evaluation of fibrosis and apoptosis in glomerulus and tubular cells. Contrary to our results, apoptosis was markedly decreased in the kidneys of neonatal SHRs compared with their normotensive controls [36]. Nevertheless, it should be noted that the cited study was conducted in newborn SHRs within the first week of life, a period when we did not find significant changes. Previously, we had demonstrated an increase on renal interstitial fibrosis and apoptosis in adult SHRs [10]. However, this is the first study using the essential hypertension model which established a lesser WT-1 expression level occurring parallel to renal morphometric changes during late renal development and its consolidation as an adult organ. This is a key finding, considering that nephrogenesis in rats continues many days after birth. Thus, renal development in the newborn rat is comparable to that of the midtrimester human fetus, while renal maturation in the 


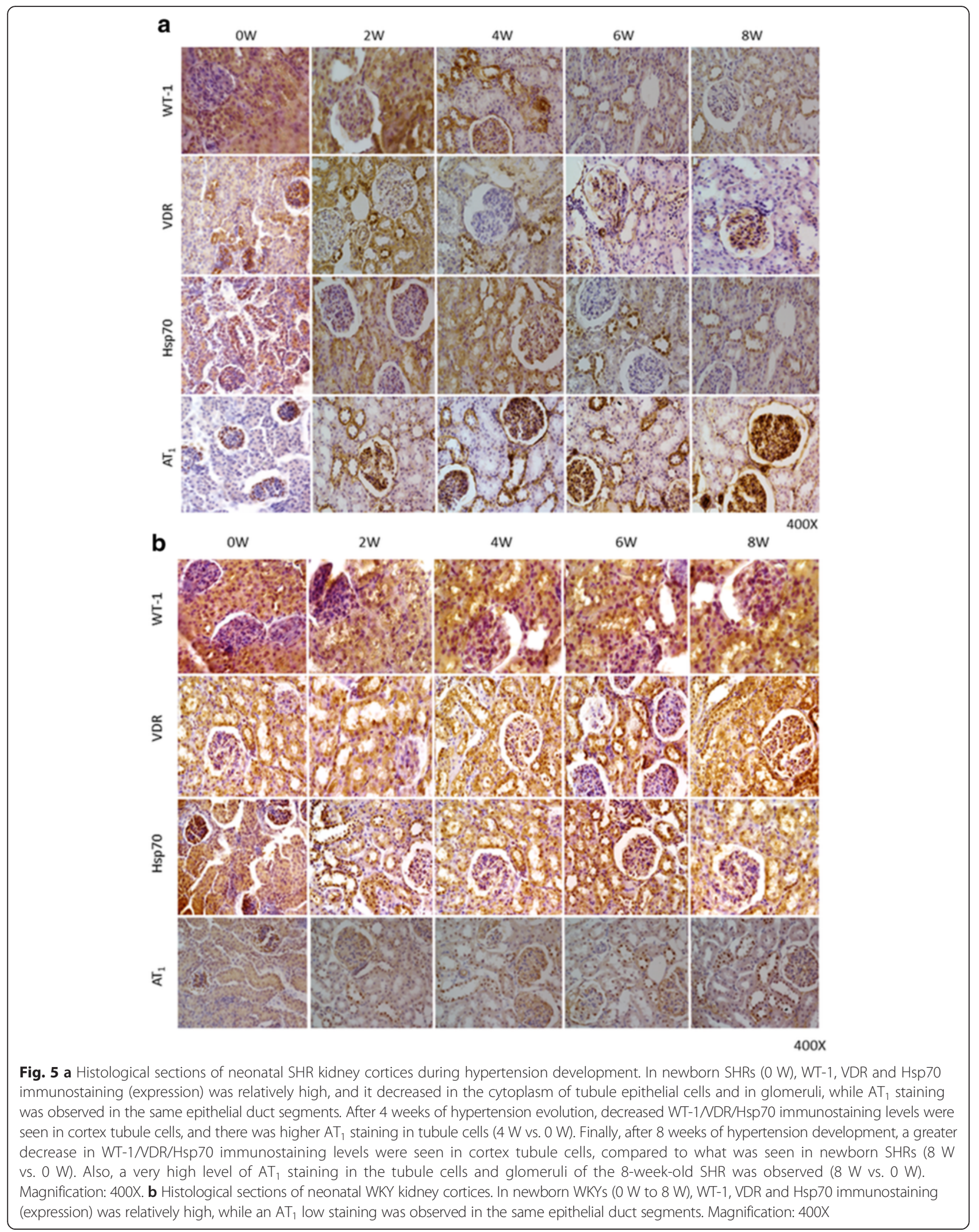


a
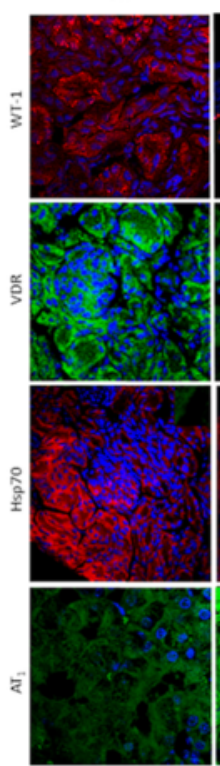

4 W
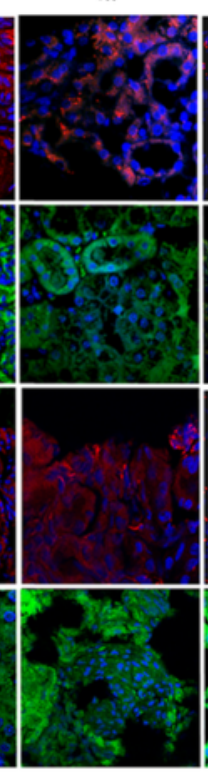

$8 w$
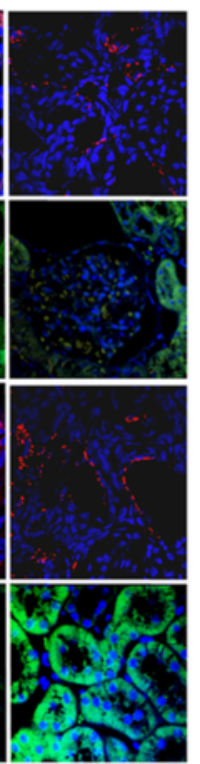

b
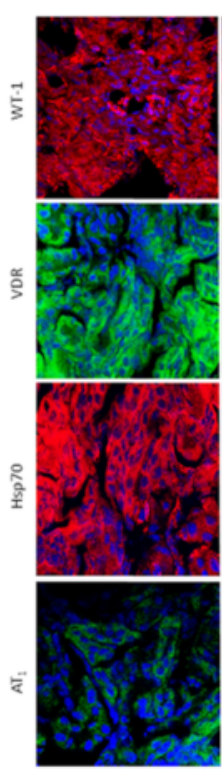

$4 \mathrm{~W}$

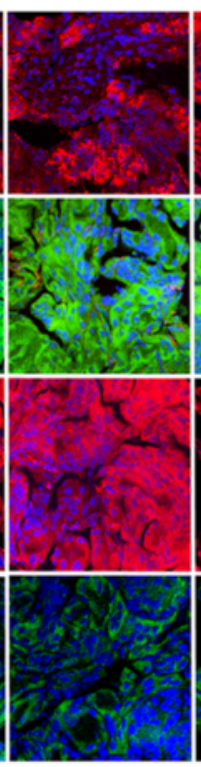

$8 w$

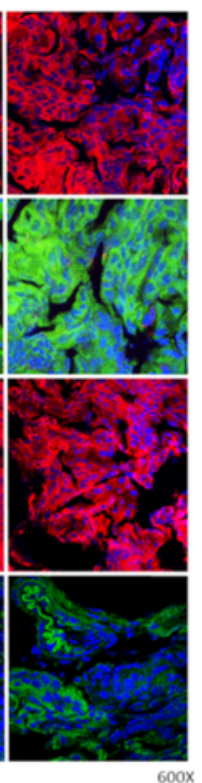

Fig. 6 a Immunofluorescence confocal microscopy study in SHRs. Immunofluorescence/cytochemical localization of WT-1, VDR, Hsp70 and AT 1 in kidney cortices from SHR rats. Renal cortex tissues were labeled with antibodies against WT-1, VDR, Hsp70 and AT, followed by anti-rabbit fluorescein isothiocyanate-conjugated, and anti-mouse Rhodamine Red and Green X-conjugated secondary antibodies. Nuclei were stained with Hoechst 33342 (blue). Images represent five different experiments. In tubule epithelial cells of the newborn SHR (0 W), greater WT-1 (red), VDR (green) and Hsp70 (red) staining were identified. Similarly, basal expression of $\mathrm{AT}_{1}$ (green) appears in the tubule epithelial cells. Surprisingly, at week 4 of hypertension development, immunoreactive WT-1, VDR and Hsp70 decreased in the cytosol and the membrane of epithelial tubule cells. In addition, at week 8, these parameters were very low. Contrarily, at week 4 of hypertension development, immunoreactive $A T_{1}$ in the cytosol and the membrane of epithelial tubule cells increased, and at week 8, it was very high. Magnification: 600X. b Immunofluorescence confocal microscopy study in WKYs. Immunofluorescence/cytochemical localization of WT-1, VDR, Hsp70 and AT in kidney cortices from WKY rats. Renal cortex tissues were labeled with antibodies against WT-1, VDR, Hsp70 and AT 1 followed by anti-rabbit fluorescein isothiocyanate-conjugated, and anti-mouse Rhodamine Red and Green X-conjugated secondary antibodies. Nuclei were stained with Hoechst 33342 (blue). Images represent five different experiments. In tubule epithelial cells of the newborn WKY (0 W to 8 W), high WT-1 (red), VDR (green) and Hsp70 (red) staining were identified. In addition, a low expression of AT 1 (green) appears in the tubule epithelial cells. Interesting, at week 8, immunoreactive WT-1, VDR and Hsp70 not decreased in the cytosol and the membrane of epithelial tubule cells. Also, at week 8, immunoreactive AT 1 not increased in the cytosol and the membrane of epithelial tubule cells. Magnification: 600X

2-week-old rat is analogous to that of the human infant [37]. Interestingly, Dr. Chevalier demonstrated that renal growth is impaired and nephron number is reduced in 14- to 19-day-old rats with obstructive nephropathy [38]. Using the same model, we have reported a significantly low expression of WT-1 in neonatal rats linked to glomerular changes and reduced nephrogenic markers [32]. Hence, kidney impairment is a significant event in hypertension development and, thus, alteration of a key nephrogenic gene expression such as WT-1 appears to contribute to hypertension development.

On the other hand, recent studies in hypertension have shown low levels of vitamin $D$ linked to RAAS exaltation [6, 39, 40]. Moreover, Hsp70 regulates signaling pathway responses to cellular oxidative stress; and, in that respect, our laboratory has shown that Hsp70 protects against angiotensin II-induced hypertension [9]. We examined the effect of losartan on the expression/ localization of Hsp70 in primary cultures of proximal tubular cells of SHRs, and demonstrated that the membrane translocation of Hsp70 could exert a protective effect by reducing the activity and expression of NADPH oxidase. In line with these studies, we also demonstrated in adults SHRs that structural and functional changes were reversed by VDR induction and that the association with enalapril worked even better. Thus, our recent data suggest that a low $\mathrm{AT}_{1}$ expression through VDR induction could be a consequence of Hsp70-mediated cell protection [10]. These concepts could be critical in understanding the complex interplay between VDR and RAAS for hypertension and related inflammatory disorders. Unprecedentedly, and occurring previous to the increase in blood pressure, we demonstrated low expressions of VDR and Hsp70 linked to a poor WT-1 level in the renal cortices from 4-week-old SHRs. Contrary to this, $\mathrm{AT}_{1}$ staining was observed in the same SHR epithelial cells. These values were very significant in 8-weekold rats. These data are revealing in the light of previous 


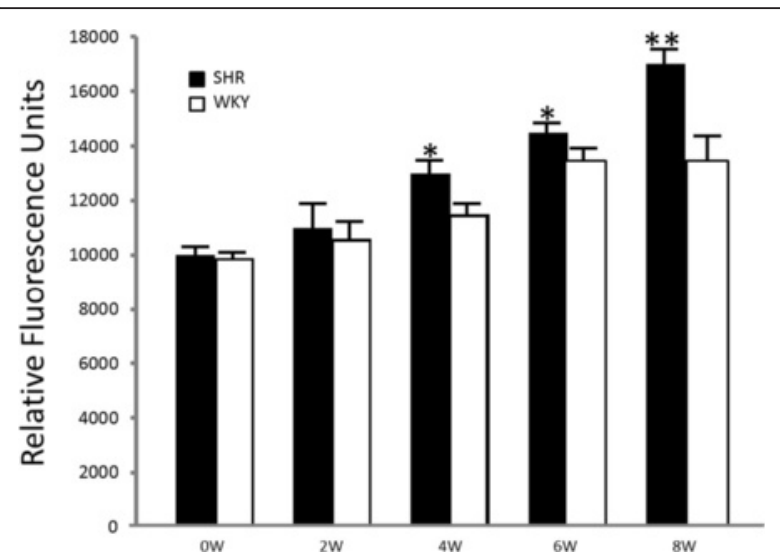

Fig. $7 \mathrm{NADPH}$ activity in mitochondrial fractions from renal cortices during hypertension development. NADPH oxidase activity was observed in SHRs and WKYs: newborn rats $(0 \mathrm{~W})$, 2-week-old rats (2 W), 4-week-old rats (4 W), 6-week-old rats ( $6 \mathrm{~W}$ ) and 8-week-old rats (8 W). Specifically, NADPH oxidase activity in mitochondrial fractions from kidney cortices increased at week 4 and 6 of hypertension evolution $\left(^{*} p\right.$ $<0.05$, both ages), while it was considerably higher only in the 8-weekold SHR, compared to the normotensive control $(W K Y)\left({ }^{* *} p<0.01\right)$. Each bar represents mean $\pm \mathrm{SEM} ; n=5$

contributions. WT-1 and Hsp70 are physically associated in rat kidney cells, in primary Wilms' tumor samples and in cultured cells with inducible expression of WT-1. Hsp70 is recruited to the characteristic sub-nuclear clusters containing WT-1. In addition, WT-1 requires amino-terminal transactivation domain for binding to Hsp70, and the expression of that domain itself is sufficient to induce the expression of Hsp70. Replacing the Hsp70 binding domain is sufficient to restore the functional properties of WT-1. These observations indicate that Hsp70 is an important cofactor for the function of WT-1, and suggest an emergent role of Hsp70 during nephrogenesis [11]. VDR, a ligand-activated transcription factor, is also regulated by WT-1. In humans, multiple assays suggested that, while WT- 1 can choose from three binding sites within the VDR promoter, the VDR gene activation seems to occur through a single site. This site differs from a site-sensitive WT-1 previously identified in the murine VDR promoter [12]. Accordingly, the evidence suggests that there could be a modulation between Hsp70, VDR and WT-1. Moreover, the decoupling between Hsp70 and VDR associated with a possible poor expression of WT-1 could be keys to hypertension development.

In the present study, we have demonstrated that there was ultrastructural damage at the mitochondrial level in the renal cortices of neonatal SHRs. In addition, a presence of high $\mathrm{AT}_{1}$ and $\mathrm{NADPH}$ oxidase activity coupled with low WT-1, VDR and Hsp70 expressions were consistent with the histological and structural changes demonstrated. Importantly, hypertensive-induced renal injury is characterized by activation of several deleterious pathways, including oxidative stress, RAAS, renal remodeling, poor vitamin D levels and apoptosis, all of which may compromise mitochondrial integrity and function. Mitochondria are the main generators of reactive oxygen species (ROS) in cells, yet their pathophysiological role in hypertension and related inflammatory diseases remains to be fully clarified [13]. Mitochondrial dysfunction has been implicated in the etiology of many diseases, like hypertension, and, among the many factors involved, our laboratory has characterized in mitochondria the RAAS exaltation and deficiency of vitamin D receptor $[6,10,39]$. In this paper, we have demonstrated that proximal convoluted tubules display normal tubular cells with baseline projections within normal parameters. They had abundant mitochondria, mostly with normal ultrastructure, except for some beginning to show changes, such as wider spaces than expected between the mitochondrial cristae. Moreover, in 8-week-old SRHs, the architecture of the renal tissue was disorganized, and the cellular structure was also altered. These cells contained vacuoles, mitochondria with cristae separated by widened spaces between them -some of them containing vacuoles and dense bodies surrounded by membranes. In the last decade, it has been shown that ROS and inflammation, with special attention to mitochondria, play an important role in the development of hypertension $[13,41]$. In this regard, our laboratory proposed a complex interplay between inflammatory pathway regulation and Hsp70 [42]. One mechanism that has recently been discussed by our work group and other laboratories is the possible involvement of Hsp70 and WT-1 on mitochondrial signaling pathway, where the net effect would favor cell survival by WT- 1 stabilizing $\mathrm{Bcl}_{2}$, and would limit the potential for release of cytochrome $\mathrm{C}$ from mitochondria [15]. Also, Hsp70 interacts with the VDR and plays a role in controlling VDR concentrations within cells [43]. Vitamin D has also been demonstrated to be a nontoxic inducer of Hsp70 in the rat kidney [44]. NADPH oxidase activity was reverted in mitochondrial fractions from vitamin D inducer-treated animals [19]. Furthermore, VDR-modulated $\mathrm{Hsp} 70 / \mathrm{AT}_{1}$ expression may protect the structure and function of SHR kidneys [10]. In addition, transcriptional activation of the VDR by WT-1 can mediate programmed death of renal embryonic cells in response to $1,25-(\mathrm{OH})(2) \mathrm{D}(3)$ [45]. Thus, previous evidence and our present findings support a key role of the vitamin $\mathrm{D}$ endocrine system in renal cell growth and differentiation during hypertension development. Moreover and in accordance with our current findings, maternal vitamin D deficiency accompanies changes in the expression of important renal factors that can slow maturation of glomeruli, extending the period of nephrogenesis [46].

Collectively, we propose an original hypothesis holding mitochondrial dysfunction as a precursor of hypertension. 
The potential for interaction between Hsp70 and VDR in mitochondria could be a cause or consequence of WT-1 modulation (Fig. 8, proposed hypothesis graph).

\section{Conclusions}

The originality of the proposal presented in this paper is the idea that, in the natural history of hypertension, ultrastructural mitochondrial damage occurs first, before hemodynamic clinical manifestations appear. The altered mitochondrial energy metabolism linked to master nephrogenic factors, such as WT-1, could play a central role in the essential hypertension model, and should be further investigated. Unprecedentedly, we show opposing relationships between blood pressure levels in relation to the WT-1 nephrogenic factor and related genes. To our knowledge, this is the first study that finds that hypertension may be a result of possible changes in renal development by decoupling organogenic key factors. Finally, although the relationship between hypertension and kidney disease remains unclear and a matter of considerable interest for research, our current results provide new evidence suggesting that essential hypertension would result as a consequence of kidney disease with nephrogenic disturbances. Further studies should be designed to validate our findings and allow the implementation of novel therapeutic tools for hypertension.

\section{Availability of data and materials}

The authors state that all the data supporting your findings is contained within the manuscript.

\section{Ethics approval}

The authors ensure that the manuscript adheres to ARRIVE guidelines. Animals were cared in accordance with the Guiding Principles in the Care and Use of Animals

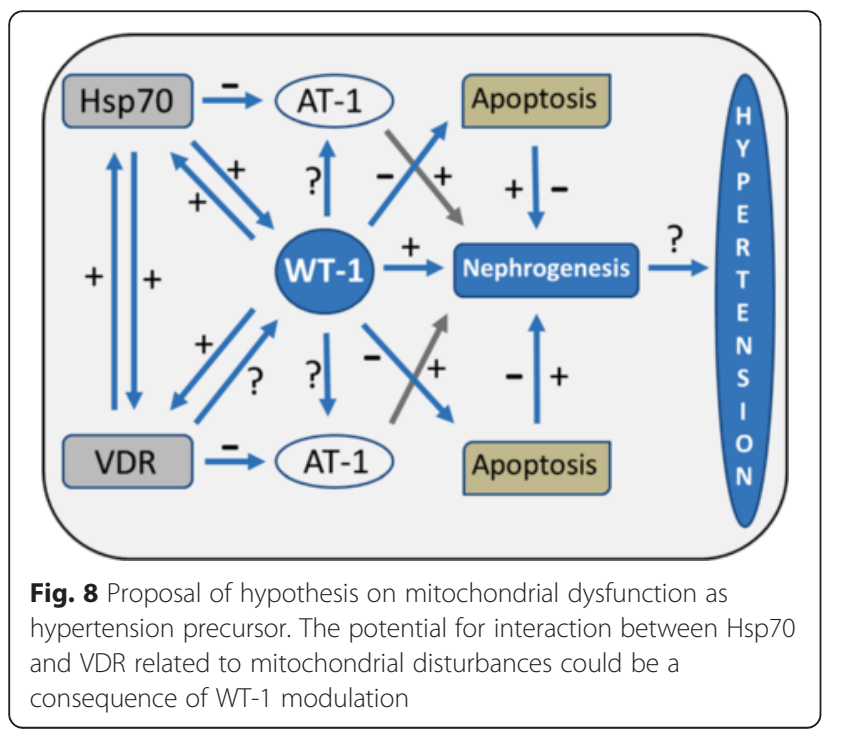

of the United States National Institute of Health. All experimental procedures were previously approved by the Institutional Animal Care and Use Committee of the Medical Sciences College, National University of Cuyo (Protocol approval $\left.N^{\circ} 46 / 2015\right)$.

\section{Additional files}

Additional file 1: Data S1. RT-PCR expression in SHRs cortex kidney. Representative gel of WT-1, VDR, Hsp70 and $A T_{1}$ mRNA expression in SHRs cortex kidney. Housekeeping gene $\beta$-actin expression is shown in the line here below. (TIF $26384 \mathrm{~kb}$ )

Additional file 2: Data S2. Protein expression in SHRs cortex kidney. Representative blot of WT-1, VDR, Hsp70 and AT protein expression in SHRs cortex kidney. Housekeeping gene $\beta$-actin protein expression is shown in the line here below. (TIF $26384 \mathrm{~kb}$ )

\section{Abbreviations}

$\mathrm{AT}_{1}$ : angiotensin II receptor, type $1 ; \mathrm{BCl}_{2}$ : B-cell lymphoma 2; BMP7: morphogenetic protein 7; Hsp70: heat shock protein 70; KTS: retinoblastoma-like protein 1; NADPH: nicotinamide adenine dinucleotide phosphate-oxidase; NS: not significant; RAAS: renin-angiotensinaldosterone system; RFU: relative fluorescence units; ROS: reactive oxidative stress; SBP: systolic blood pressure; SHR: spontaneously hypertensive rats; TUNEL: terminal deoxynucleotidyl transferase dUTP nick end labeling; VDR: vitamin D receptor; WKY: Wistar-Kyoto rats; WT-1: Wilms' tumor transcription factor 1 .

\section{Competing interests}

The author(s) declared no potential conflicts of interest with respect to the research, authorship, and/or publication of this article.

\section{Authors' contributions}

WM and LF contributed to conception and design of the study, with substantial contribution to data acquisition, analysis and interpretation of the data, drafting of the article, and critical revision of the article for intellectual content. LM, MG, JPC, MC performed the animal procedures with contribution to data acquisition, analysis and interpretation. MAA performed the biochemical determinations. DCC performed the immunohistochemical studies. MF performed the electron microscopy. All authors read and approved the final manuscript.

\section{Acknowledgement}

Our thanks to Claudia Bottero for improving the style and grammar of the text.

\section{Funding}

The author(s) disclosed receipt of the following financial support for the research, authorship, and/or publication of this article: This work was supported by grants from the Research and Technology Council of Cuyo University (SECyT), Mendoza, Argentina, and from the National Council of Scientific and Technical Research (CONICET) PIP 2010-2012, both of which were awarded to Walter Manucha. Grant no. PICT 2012-0234, BID 2777 OC/AR.

\section{Author details \\ ${ }^{1}$ National Scientific and Technical Research Council, Institute of Medical and Experimental Biology of Cuyo, Mendoza, Argentina. ${ }^{2}$ Pathology Department, Pharmacology Area Medical Sciences College, National University of Cuyo, Mendoza CP5500, Argentina. ${ }^{3}$ National Scientific and Technical Research Council, Institute of Histology and Embryology of Mendoza, Mendoza, Argentina. ${ }^{4}$ Department of Physiology and Pharmacology, School of Medicine, Puerto Rico University, Puerto Rico, EEUU, USA.}

Received: 11 November 2015 Accepted: 18 March 2016 Published online: 24 March 2016

References

1. Padmanabhan S, Caulfield M, Dominiczak AF. Genetic and molecular aspects of hypertension. Circ Res. 2015;116:937-59. 
2. Lankadeva YR, Singh RR, Tare M, Moritz KM, Denton KM. Loss of a kidney during fetal life: long-term consequences and lessons learned. Am J Physiol Renal Physiol. 2014;306:F791-800.

3. Menendez-Castro C, Hilgers KF, Amann K, Daniel C, Cordasic N, Wachtveitl R, Fahlbusch F, Plank C, Dötsch J, Rascher W, Hartner A. Intrauterine growth restriction leads to a dysregulation of Wilms' tumour supressor gene 1 (WT1) and to early podocyte alterations. Nephrol Dial Transplant. 2013;28:1407-17.

4. Abdel-Hakeem AK, Henry TQ, Magee TR, Desai M, Ross MG, Mansano RZ, Torday JS, Nast CC. Mechanisms of impaired nephrogenesis with fetal growth restriction: altered renal transcription and growth factor expression. Am J Obstet Gynecol. 2008;199:252.e1-7.

5. Steege A, Fähling M, Paliege A, Bondke A, Kirschner KM, Martinka P, Kaps C, Patzak A, Persson PB, Thiele BJ, Scholz H, Mrowka R. Wilms' tumor protein (-KTS) modulates renin gene transcription. Kidney Int. 2008;74:458-66.

6. Ferder M, Inserra F, Manucha W, Ferder L. The world pandemic of vitamin D deficiency could possibly be explained by cellular inflammatory response activity induced by the renin-angiotensin system. Am J Physiol Cell Physiol. 2013;304:C1027-39.

7. Skov J, Persson F, Frøkiær J, Christiansen JS. Tissue Renin-Angiotensin systems: a unifying hypothesis of metabolic disease. Front Endocrinol (Lausanne). 2014;5:23. doi:10.3389/fendo.2014.00023. eCollection 2014.

8. Santoro D, Caccamo D, Lucisano S, Buemi M, Sebekova K, Teta D, De Nicola L. Interplay of vitamin D, erythropoiesis, and the renin-angiotensin system. Biomed Res Int. 2015;2015:145828.

9. Bocanegra V, Manucha W, Peña MR, Cacciamani V, Vallés PG. Caveolin-1 and Hsp70 interaction in microdissected proximal tubules from spontaneously hypertensive rats as an effect of Losartan. J Hypertens. 2010;28:143-55.

10. García IM, Altamirano L, Mazzei L, Fornés M, Cuello-Carrión FD, Ferder L, Manucha W. Vitamin D receptor-modulated Hsp70/AT1 expression may protect the kidneys of SHRs at the structural and functional levels. Cell Stress Chaperones. 2014;19:479-91.

11. Maheswaran S, Englert C, Zheng G, Lee SB, Wong J, Harkin DP, Bean J, Ezzell R, Garvin AJ, McCluskey RT, DeCaprio JA, Haber DA. Inhibition of cellular proliferation by the Wilms tumor suppressor WT1 requires association with the inducible chaperone Hsp70. Genes Dev. 1998;12:1108-20.

12. Lee TH, Pelletier J. Functional characterization of WT1 binding sites within the human vitamin D receptor gene promoter. Physiol Genomics. 2001;7:187-200.

13. Nazarewicz RR, Dikalov SI. Mitochondrial ROS in the prohypertensive immune response. Am J Physiol Regul Integr Comp Physiol. 2013;305:R98-100.

14. Mikhed Y, Daiber A, Steven S. Mitochondrial Oxidative Stress, Mitochondrial DNA Damage and Their Role in Age-Related Vascular Dysfunction. Int J Mol Sci. 2015;16:15918-53.

15. Mazzei L, Docherty NG, Manucha W. Mediators and mechanisms of heat shock protein 70 based cytoprotection in obstructive nephropathy. Cell Stress Chaperones. 2015. doi:10.1007/s12192-015-0622-z.

16. Dornas WC, Silva ME. Animal models for the study of arterial hypertension. J Biosci. 2011;36:731-7.

17. Masson PJ. J Tech Methods. 1929;12:75-90.

18. Hruska KA, Guo G, Wozniak M, Martin D, Miller S, Liapis H, Loveday K, Klahr S, Sampath TK, Morrissey. J Osteogenic protein-1 prevents renal fibrogenesis associated with ureteral obstruction. Am J Physiol Renal Physiol. 2000;279: F130-43.

19. Morrissey J, Hruska K, Guo G, Wang S, Chen Q, Klahr S. Bone morphometric protein-7 improves renal fibrosis and accelerates the return of renal function. J Am Soc Nephrol. 2002;13:S14-21.

20. García IM, Altamirano L, Mazzei L, Fornés M, Molina MN, Ferder L, Manucha W. Role of mitochondria in paricalcitol-mediated cytoprotection during obstructive nephropathy. Am J Physiol Renal Physiol. 2012;302:F1595-605.

21. García IM, Mazzei L, Benardón ME, Oliveros L, Cuello-Carrión FD, Gil Lorenzo A, Manucha W, Vallés PG. Caveolin-1-eNOS/Hsp70 interactions mediate rosuvastatin antifibrotic effects in neonatal obstructive nephropathy. Nitric Oxide. 2012;27(2):95-105

22. Ciocca DR, Cuello-Carrión FD, Natoli AL, Restall C, Anderson RL. Absence of caveolin-1 alters heat shock protein expression in spontaneous mammary tumors driven by Her-2/neu expression. Histochem Cell Biol. 2012;137(2):187-94.

23. Gago FE, Tello OM, Diblasi AM, Ciocca DR. Integration of estrogen and progesterone receptors with pathological and molecular prognostic factors in breast cancer patients. J Steroid Biochem Mol Biol. 1998;67: $431-7$.

24. Greenawalt JW. The isolation of outer and inner mitochondrial membranes. Methods Enzymol. 1974:31:310-23.

25. O'Beirne GB, Williams DC. The subcellular location in rat kidney of the peripheral benzodiazepine acceptor. Eur J Biochem. 1988;175:413-21.

26. Ekblom P. Developmentally regulated conversion of mesenchime to epithelium. FASEB J. 1989;3:2141-60.

27. Pritchard-Jones K, Fleming S, Davidson D, Bickmore W, Porteous D, Gosden C, Bard J, Buckler A, Pelletier J, Housman D, Van Heinigen V, Hastie N. The candidate Wilms tumor gene is involved in genitourinary development. Nature. 1990;346:194-7.

28. Kreidberg JA, Sariola H, Loring JM, Maeda M, Pelletier J, Housman D, Jaenisch R. WT1 is required for early kidney development. Cell. 1993;74:679-91.

29. Burrow C, Wilson PD. A putative tumor-secreted growth factor activity required for primary culture of human nephroblast. Proc Natl Acad Sci U S A. 1993;90:6066-70.

30. Rupprecht HD, Drummond IA, Madden SL, Rauscher III FJ, Sukhatme VP. The Wilms' tumor suppressor gene WT1 is negatively autoregulated. J Biol Chem. 1994;269:6198-202.

31. Hohenstein P, Pritchard-Jones K, Charlton J. The yin and yang of kidney development and Wilms' tumors. Genes Dev. 2015:29:467-82.

32. Mazzei LJ, García IM, Altamirano L, Docherty NG, Manucha W. Rosuvastatin preserves renal structure following unilateral ureteric obstruction in the neonatal rat. Am J Nephrol. 2012;35:103-13.

33. Liapis H. Biology of congenital obstructive nephropathy. Nephron Exp Nephrol. 2003;93:87-91.

34. Menke AL, Schedl A. WT1 and glomerular function. Semin Cell Dev Biol. 2003;14:233-40.

35. Menke AL, Hastie ND. Wilms' tumor: a developmental anomaly. In: Fisher DE, editor. Tumor suppressor genes in human cancer. 1st ed. Totowa: Humana Press; 2001. p. 307.

36. Moreau P, Tea BS, Dam TV, Hamet P. Altered balance between cell replication and apoptosis in hearts and kidneys of newborn SHR. Hypertension. 1997;30:720-4.

37. Chevalier RL. Obstructive nephropathy and the developing kidney: Too little or too much angiotensin? Kidney Int. 2004;65:1517-8.

38. Chevalier RL, Thornhill BA, Chang AY, Cachat F, Lackey A. Recovery from release of ureteral obstruction in the rat: Relationship to nephrogenesis. Kidney Int. 2002;61:2033-43.

39. Manucha W, Ritchie B, Ferder L. Hypertension and insulin resistance: implications of mitochondrial dysfunction. Curr Hypertens Rep. 2015;17:504. doi:10.1007/s11906-014-0504-2.

40. Carbone F, Mach F, Vuilleumier N, Montecucco F. Potential pathophysiological role for the vitamin D deficiency in essential hypertension. World J Cardiol. 2014;6:260-76.

41. Sinha N, Dabla PK. Oxidative stress and antioxidants in hypertension -a current review. Curr Hypertens Rev. 2015; May 29. [Epub ahead of print].

42. Manucha W. HSP70 Family in the Renal Inflammatory Response. Inflamm Allergy Drug Targets. 2014;13:235-40.

43. Lutz W, Kohno K, Kumar R. The role of heat shock protein 70 in vitamin D receptor function. Biochem Biophys Res Commun. 2001;282:1211-9.

44. Kim YO, Li C, Sun BK, Kim JS, Lim SW, Choi BS, Kim YS, Kim J, Bang BK, Yang CW. Preconditioning with 1,25-dihydroxyvitamin D3 protects against subsequent ischemia reperfusion injury in the rat kidney. Nephron Exp Nephrol. 2005;100:e85-94.

45. Wagner KD, Wagner N, Sukhatme VP, Scholz H. Activation of vitamin D receptor by the Wilms' tumor gene product mediates apoptosis of renal cells. J Am Soc Nephrol. 2001;12:1188-96.

46. Nascimento FA, Ceciliano TC, Aguila MB, Mandarim-de-Lacerda CA. Maternal vitamin D deficiency delays glomerular maturity in F1 and F2 offspring. PLoS One. 2012;7, e41740. doi:10.1371/journal.pone.0041740. 